\title{
P-Chiral Phosphoramidates from a Catalytic Asymmetric Halocyclization
}

\section{Key words}

halocyclization

phosphoramidates

P-chiral compounds<smiles>[R]C=C([R])CN(C[R])P(=O)(O)OC</smiles>

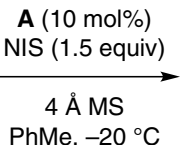

$\mathrm{R}^{1}=$ Alk, Ar, $\mathrm{H}$

$\mathrm{R}^{2}=\mathrm{H}, \mathrm{Me}$

$\mathrm{R}^{3}=\mathrm{Ar}$

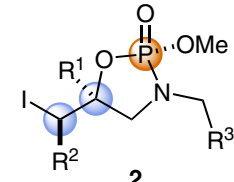

11 examples

$69-95 \%$ yield

dr from $1: 1$ to $>20: 1$ er from $84: 16$ to $99: 1$

Selected examples:<smiles>CO[P+]1(=O)OC(CI)(c2ccccc2)CN1Cc1ccccc1</smiles>

$85 \%$ yield $\mathrm{dr}>20: 1$ er $=98: 2$

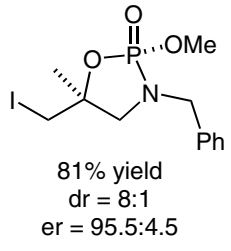

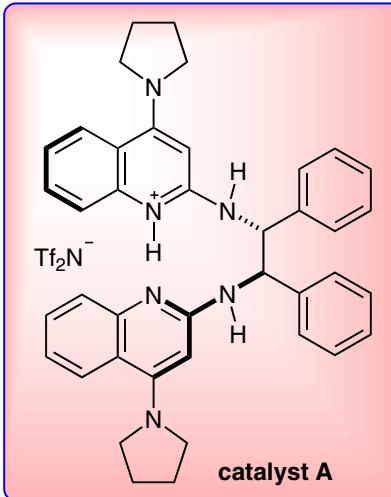<smiles>C=CC1CC2(CC(C)N(Cc3ccccc3)C2)OP1(=O)OC</smiles>

\section{$92 \%$ yield}

$\mathrm{dr}>20: 1$ er $=99: 1$

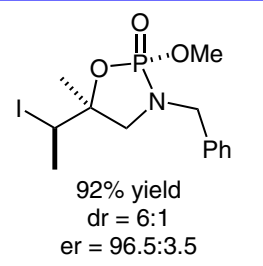

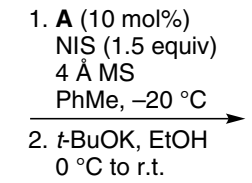

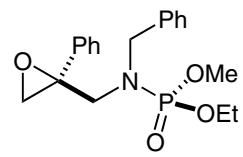

$69 \%$ overall yield $\mathrm{dr}=8: 1, \mathrm{er}=97: 3$
Significance: The Johnston group reports an organocatalytic asymmetric iodocyclization for the synthesis of cyclic phosphoramidates bearing Cand $\mathrm{P}$-chiral centers. The methodology relies on the previously reported catalytic system based on the combination of an achiral Brønsted acid and a chiral enantiopure Brønsted base A. Using N-iodosuccinimide (NIS) as an electrophilic source of iodine, the desired products $\mathbf{2}$ are obtained under very mild conditions in good yields and in good to excellent enantioselectivities. Notably, if coupled with a simple basic treatment, the transformation is an interesting alternative to asymmetric epoxidations of allylamine derivatives.

SYNFACTS Contributors: Benjamin List, Mattia Riccardo Monaco Synfacts 2015, 11(1), 0093 Published online: 15.12.2014 Dol: 10.1055/s-0034-1379621; Reg-No.: B12314SF
Comment: Phosphorous-containing compounds largely occur as pharmaceuticals and agrochemicals; thus, significant interest is focused on the development of procedures for their preparation. Interestingly however, despite chirality often being a crucial issue for marketed substances, there is a general lack of catalytic methodologies for the enantioselective synthesis of P-chiral compounds. Here, the authors tackle the challenge disclosing the first organocatalytic protocol for this goal. The synthetic value of the methodology is highlighted by the conversion of the cyclic products into acyclic compounds in a stereospecific process. 